\title{
PAR1-Mediated RhoA Activation Facilitates CCL2-Induced Chemotaxis in PC-3 Cells
}

\author{
Robert D. Loberg, ${ }^{*}$ Kwanchanit Tantivejkul, Matthew Craig, Chris K. Neeley, and Kenneth J. Pienta \\ Departments of Urology and Internal Medicine, Division of Hematology and Oncology, \\ University of Michigan Comprehensive Cancer Center, Ann Arbor, Michigan 48109
}

\begin{abstract}
Patients with advanced prostate cancer often exhibit increased activation of the coagulation system. The key activator of the coagulation cascade is the serine protease thrombin which is capable of eliciting numerous cellular responses. We previously reported that the thrombin receptor PAR1 is overexpressed in prostate cancer. To investigate further the role of PAR1 in prostate cancer metastasis, we examined the effects of thrombin activation on cell adhesion and motility in PC-3 prostate cancer cells. Activation of PAR1-induced dynamic cytoskeletal reorganization and reduced PC-3 binding to collagen I, collagen IV, and laminin $(P<0.01)$ but not fibronectin. Expression of the cell surface integrin receptors did not change as assessed by flow cytometry. Immunofluorescence microscopy revealed that PAR1 stimulation caused reorganization of the focal adhesions, suggesting that PAR1 activation in PC-3 cells may be modulating cell adhesion through integrin function but not expression. Furthermore, RhoA was activated upon stimulation with thrombin with subsequent cell contraction, decreased cell adhesion, and induced migration towards monocyte chemoattractant protein 1 (MCP-1; CCL2). Thus, it appears that thrombin stimulation plays a role in prostate cancer metastasis by decreasing cell adhesion to the extracellular matrix and positioning the cell in a "ready state" for migration in response to a chemotactic signal. Further exploration is needed to determine whether PAR1 activation affects other signaling pathways involved in prostate cancer. J. Cell. Biochem. 101: 1292-1300, 2007. ๑ 2007 Wiley-Liss, Inc.
\end{abstract}

Key words: Rho GTPases; integrins; thrombin; monocyte chemoattractant protein 1; migration

Cytoskeletal organization is regulated by the $R$ as homolog superfamily of small guanosine triphosphatases, better known as Rho GTPases, which share approximately $35 \%$ sequence identity with proteins of the Ras superfamily. The activation of Rho GTPases is necessary for signaling between cells and extracellular matrix (ECM) and for maintenance of cell shape and associated focal adhesion complexes [Burridge and Wennerberg, 2004]. To date, at least 20 family members have been described with Rho, Rac, and Cdc42 the best-characterized [Burridge and Wennerberg, 2004]. Rho is responsible for maintaining cell shape and cell

Grant sponsor: SPORE; Grant number: 1 P50 CA69568-06A1; Grant sponsor: RO1; Grant number: CA102871; Grant sponsor: NIH; Grant number: 1 P01 CA093900-01A2.

*Correspondence to: Robert D. Loberg, PhD, 7312 CCGC, 1500 East Medical Center Dr., Ann Arbor, MI 48109-0946. E-mail: rloberg@umich.edu

Received 7 November 2006; Accepted 30 November 2006

DOI 10.1002/jcb.21252

(c) 2007 Wiley-Liss, Inc. contraction while Rac and Cdc42 appear to work together to induce cell migration. Rac activation induces lamellipodia and membrane ruffling and Cdc42 produces filopodia that establish cell polarity. Rac, but not Rho, is also responsible for forming focal complexes at the leading edges of the lamellipodia [Ridley, 2001]. These proteins and their associated downstream signals are often elevated in malignant tissue [Ridley, 2004]. For example, signal transduction through the activation of Rac and Cdc42 has been implicated in the invasive potential of cancer cells [Ridley, 2001].

Regulation of the Rho GTPase family occurs through cross talks between integrins and cell adhesion receptors, receptor tyrosine kinases, and $\mathrm{G}$ protein-coupled receptors (GPCRs). In recent years, mounting evidence supports the role of GPCR signaling in the pathogenesis of prostate cancer. Prostate cancer cells produce excessive amounts of GPCR ligands such as endothelin-1, lysophosphatidic acid, bradykinin, prostaglandin, and thrombin [Offermanns et al., 1994; Macrez et al., 1997; Gohla et al., 1998]. They also express higher levels of GPCRs 
including the thrombin receptor (protease activated receptor 1 or PAR1) which we have previously reported to be overexpressed in prostate cancer cells compared to normal prostate epithelium [Chay et al., 2002]. Recently, we have demonstrated that prostate cancer cells (e.g., PC-3 and $\mathrm{VCaP}$ cells) respond to monocyte chemoattractant protein 1 (MCP-1; CCL2) by increasing their rate of proliferation and migration towards CCL2 [Loberg et al., 2006]. Because PAR1 is overexpressed in metastatic prostate cancer cells and because thrombin is generated in excess in patients with advanced prostate cancer [Lind et al., 2003], we investigated the link between thrombin and prostate cancer cell migration by examining the effects of PAR1 activation on adhesion, migration, and Rho GTPase expression in prostate cancer cells and have demonstrated that stimulation of PAR1 induces a migratory phenotype that promotes prostate cancer cell migration in response to the chemotactic signal of CCL2.

\section{MATERIALS AND METHODS}

\section{Cell Culture}

PC-3 human prostate cancer cell line (ATCC, Manassas, VA) was cultured in RPMI-1640 supplemented with $10 \%$ fetal bovine serum (FBS) and 1\% penicillin/streptomycin/amphotericin B (Invitrogen Corp., Carlsbad, CA) at $37^{\circ} \mathrm{C}$ in a humidified incubator with $5 \% \mathrm{CO}_{2}$. Cells were passaged by trypsinization and were detached for use in all assays by exposure for $1 \mathrm{~h}$ to $0.5 \mathrm{mM}$ EDTA in Hank's balance salt solution (HBSS). Stock solutions of $1 \mu \mathrm{M}$ thrombin (Sigma-Aldrich, St. Louis, MO) and $6 \mathrm{mM}$ TRAP (Bachem, King of Prussia, PA) were prepared in sterile distilled water and stored at $-20^{\circ} \mathrm{C}$ until use. Cells were serum-starved for $2 \mathrm{~h}$ in RPMI1640 prior to PAR1 activation. PAR1 activation was performed in serum-free RPMI-1640.

\section{Adhesion Assay}

Adhesion assay was performed as previously described [Tantivejkul et al., 2003]. Briefly, wells of 96-well flat bottom tissue culture plates were coated overnight at $4{ }^{\circ} \mathrm{C}$ with $100 \mu \mathrm{L}$ of collagen I, collagen IV, fibronectin, laminin, or vitronectin $(10 \mu \mathrm{g} / \mathrm{ml}$ in phosphate buffered saline (PBS)) (BD Biosciences, San Jose, CA). After serum starvation and EDTA-release, PC3 cells were treated for 30 min with 2 or $10 \mathrm{nM}$ thrombin or $100 \mu \mathrm{M}$ TRAP6 in RPMI-1640 containing $0.1 \% \mathrm{BSA}$ at $37^{\circ} \mathrm{C}$ with agitation. Wells coated with proteins were blocked with $0.1 \%$ BSA in RPMI- 1640 at $37^{\circ} \mathrm{C}$ for 30 min prior to the addition of $100 \mu \mathrm{L}$ of $2 \times 10^{5}$ cells $/ \mathrm{ml}$ to each well. After $30 \mathrm{~min}$ in an incubator, for experiments to plot ECM protein adhesion profiles wells were washed three times with PBS to remove unattached cells. Adherent cells were then fixed for 15 min with $4 \%$ formaldehyde in PBS and stained for 5 min with $0.5 \%$ crystal violet in $20 \%$ methanol. Acetic acid (30\% $\mathrm{v} / \mathrm{v}$ ) was used to dissolve the crystal violet, and the optical density was determined at $595 \mathrm{~nm}$ on a VersaMax Microtiter plate reader (Molecular Devices, Sunnyvale, CA). In experiments to investigate changes in ECM protein adhesion after PAR1 activation, cells were first stained with $5 \mu \mathrm{M}$ calcein AM (Molecular Probes, Inc., Eugene, OR) for 30 min before seeding onto protein-coated wells. After $30 \mathrm{~min}$ incubation, wells were washed three times with PBS to remove unattached cells. Absorbance was measured at $490 \mathrm{~nm}$ excitation and $530 \mathrm{~nm}$ emission wavelengths. Experiments were performed in triplicate and repeated twice.

\section{Flow Cytometry}

Serum-starved PC-3 cells were treated with $10 \mathrm{nM}$ thrombin in serum-free RPMI-1640 containing $1 \%$ antibiotic/antimycotic for $12 \mathrm{~h}$ before EDTA-release. Cell concentrations were adjusted to $1 \times 10^{6}$ cells $/ \mathrm{ml}$ and incubated for $1 \mathrm{~h}$ with anti- $\alpha 1$, anti- $\alpha 2$, anti- $\alpha 3$, anti- $\alpha 5$, anti- $\alpha 6$, anti- $\beta 1$, anti- $\beta 4$, anti- $\alpha \mathrm{v} \beta 3$ or anti- $\alpha \mathrm{v} \beta 5$ mouse IgGs (Chemicon International, Inc., Temecula, CA) at $4^{\circ} \mathrm{C}$. Cells were washed twice in PBS, incubated for $30 \mathrm{~min}$ with fluorescein-conjugated secondary antibodies (Molecular Probes, Inc.) at $4{ }^{\circ} \mathrm{C}$ and fixed with $4 \%$ formaldehyde in PBS prior to flow cytometry analysis using a FACScan flow cytometer (BD Biosciences, Palo Alto, CA). Experiments were performed in triplicate and repeated twice.

\section{Immunofluorescence}

For actin cytoskeleton visualization, $1 \times 10^{5}$ PC-3 cells in culture media were plated onto chambered glass slides and incubated overnight. After serum starvation, cells were treated with 2 or $10 \mathrm{nM}$ thrombin, or $100 \mu \mathrm{M}$ TRAP6 for an additional $2 \mathrm{~h}$ to activate PAR1. Cells were washed twice with PBS, fixed for $10 \mathrm{~min}$ in 
$4 \%$ formaldehyde, permeabilized for $5 \mathrm{~min}$ with $0.1 \%$ Triton X-100, and blocked for 20 min with $1 \%$ BSA prior to staining with AlexaFluor568conjugated phalloidin (Molecular Probes, Inc.), anti- $\beta 1$ integrin (BD Biosciences), or FITCconjugated anti-phosphotyrosine (Upstate Biotechnology, Lake Placid, NY). Coverslips were mounted with Prolong anti-fade mounting media (Molecular Probes, Inc.) after slides were washed twice with PBS. Analysis was performed on an Olympus FluoView 500 Laser Scanning Confocal Microscope (Olympus, Melville, NY) through The University of Michigan Microscopic Imaging Laboratory.

\section{Rho/Rac/Cdc42 Activity Assay}

Rhotekin and PAK binding assays were performed as previously described [Sander et al., 1998]. Briefly, Escherichia coli BL21 cells transformed with the glutathione S-transferase (GST)-PAK-CD (PAK-CRIB domain) construct or GST-Rhotekin Rho binding domain (GSTRBD) construct (gifts from John Collard of Netherlands Cancer Institute) were grown at $37^{\circ} \mathrm{C}$ overnight. Expression of recombinant protein was induced with $100 \mu \mathrm{M}$ isopropylthiogalactoside for $2 \mathrm{~h}$. Cells were pelleted and resuspended in lysis buffer $(50 \mathrm{mM}$ Tris- $\mathrm{HCl}$, $\mathrm{pH} 8.0,2 \mathrm{mM} \mathrm{MgCl}_{2}, 200 \mu \mathrm{M} \mathrm{Na} \mathrm{N}_{2} \mathrm{O}, 10 \%$ glycerol, $20 \%$ sucrose, $2 \mathrm{mM}$ dithiothreitol, $1 \mathrm{mM}$ benzamide, $1 \mathrm{mM}$ PMSF, $1 \mu \mathrm{g} / \mathrm{ml}$ leupeptin, $1 \mu \mathrm{g} / \mathrm{ml}$ pepstatin, and $1 \mu \mathrm{g} / \mathrm{ml}$ aprotinin). After sonication, cell lysates were centrifuged at $4^{\circ} \mathrm{C}$ for $20 \mathrm{~min}$ at $45,000 \mathrm{~g}$ and supernatant was incubated with glutathione-coupled sepharose 4B beads (Amersham Biosciences Corp., Piscataway, NJ) for $30 \mathrm{~min}$ at $4^{\circ} \mathrm{C}$. Protein bound beads were washed three times in lysis buffer and resuspended in GST-FISH buffer $(50 \mathrm{mM}$ Tris, $\mathrm{pH} 7.4,2 \mathrm{mM} \mathrm{MgCl} 2,100 \mathrm{mM} \mathrm{NaCl}, 10 \%$ glycerol, $1 \%$ NP-40, $1 \mathrm{mM}$ benzamide, $1 \mathrm{mM}$ PMSF $1 \mu \mathrm{g} / \mathrm{ml}$ leupeptin, $1 \mu \mathrm{g} / \mathrm{ml}$ pepstatin, and $1 \mu \mathrm{g} / \mathrm{ml}$ aprotinin). PC-3 cells were starved for $2 \mathrm{~h}$, stimulated with $10 \mathrm{nM}$ thrombin, washed three times with ice-cold PBS, and lysed in GST-FISH buffer. Protein concentration in the supernatant was determined by Biorad protein determination dye (Bio-Rad Laboratories, Hercules, CA). Supernatant (1 mg) was incubated with glutathione-sepharose GST-fusion protein beads for $30 \mathrm{~min}$ at $4^{\circ} \mathrm{C}$. Pull-down beads were washed three times in GST-FISH buffer, resuspended in Laemmli buffer and analyzed by Western blotting using anti-RhoA
(Cytoskeleton, Inc., Denver, CO), anti-Rac1 (Upstate USA, Charlottesville, VA), and antiCdc42 (BD Biosciences) monoclonal antibodies. Bands were visualized by ECL chemiluminescence (Promega Corp., Madison, WI) and autoradiographic intensities were quantitated using Image J software (NCI, Bethesda, MD).

\section{In Vitro Wound Assay}

Wells of 24-well tissue culture plates were coated with collagen I, collagen IV, laminin, and fibronectin $(10 \mu \mathrm{g} / \mathrm{ml})$ as described earlier. PC-3 cells $\left(1 \times 10^{5}\right)$ were seeded per well and grown to confluence. A denuded wound area was made in each well with a standard $20-200 \mu \mathrm{L}$ pipet tip, and wells were washed three times to remove any floating cells. Wounds were visualized through a Nikon Diaphot 200 microscope at $10 \times$ magnification, and images were recorded with a Nikon CoolPix990 digital camera to confirm that they were completely free of cells. Cells were treated with 2 or $10 \mathrm{nM}$ thrombin or $100 \mu \mathrm{M}$ TRAP6 for $24 \mathrm{~h}$ at $37^{\circ} \mathrm{C}$ in a cell culture incubator. Wounded areas were reimaged, and the number of cells migrated into the denuded area was counted. Experiments were performed in triplicate and repeated three times.

\section{Migration Assay}

Increasing concentrations of CCL2 $(1-100 \mathrm{ng} / \mathrm{ml})$ or conditioned media was added to the lower chamber of a 24 well plate. Cells were harvested by EDTA release and resuspended in serum free media at $5 \times 10^{4}$ cells $/ \mathrm{ml}$. Cells $\left(2.5 \times 10^{4}\right)$ were added to the upper chamber of the transwell insert and incubated for $24 \mathrm{~h}$ at $37^{\circ} \mathrm{C}$ and $5 \%$ $\mathrm{CO}_{2}$ atmosphere. At the end of the incubation period, the cells were fixed with $4 \%$ formaldehyde in PBS for $5 \mathrm{~min}$. Non-adherent cells were removed from inside the inserts with cottontipped swab. Cells which had migrated to the underside of the insert were stained with $0.5 \%$ crystal violet for $5 \mathrm{~min}$ and rinsed thoroughly with tap water. Inserts were allowed to dry and the cells were counted using an inverted microscope.

\section{Statistical Analysis}

Results were expressed as mean \pm standard deviation of triplicates. Statistical analysis was performed using the two-tailed Student's $t$-test. A $P$-value of less than 0.05 or better was considered significant. 


\section{RESULTS}

\section{PAR1 Stimulation Decreases Cell Adhesion to ECM}

To investigate the effects of PAR1 activation on prostate cancer cell adhesion to proteins of the ECM, we first determined the cell adhesion potential of PC-3 cells on collagen I, collagen IV, fibronectin, laminin, and vitronectin. PC-3 cells preferentially adhered to collagen more than laminin, fibronectin, and vitronectin (Fig. 1A). At $0.1 \mu \mathrm{g} / \mathrm{ml}$ protein coating concentration, $\mathrm{PC}-3$ cells bound to collagens I and IV 2- to 3 -fold higher than laminin, fibronectin, or vitronectin. Cells adhered minimally to vitronectin even at high protein concentrations. Upon PAR1 activation by thrombin or TRAP6, PC-3 cell adhesion to collagen I, collagen IV, and laminin

A

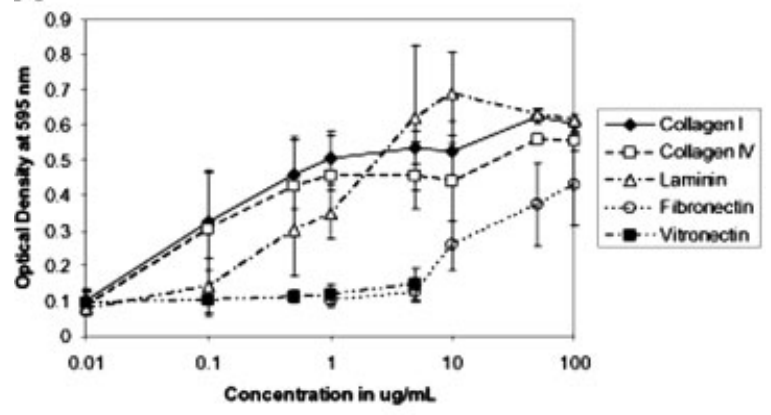

B

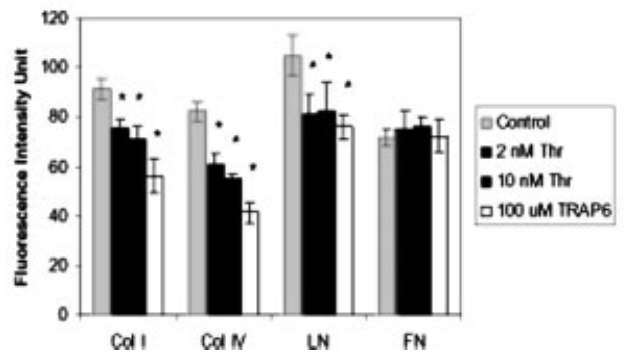

Fig. 1. PAR1 activation influences PC-3 adhesion. A: Using a range of ECM protein concentrations, adhesion profiles were generated for untreated PC-3 cells. The highest binding affinity was to collagen I and collagen IV as indicated by higher optical density at $595 \mathrm{~nm}$ after crystal violet staining at lower protein concentrations (X axis) compared to laminin, fibronectin and vitronectin. B: PAR1 activation significantly decreased cell adhesion to collagen I (Col I, $0.1 \mu \mathrm{g} / \mathrm{ml})$, collagen IV (Col IV, $0.1 \mu \mathrm{g} / \mathrm{ml})$ and laminin $(\mathrm{LN}, 1 \mu \mathrm{g} / \mathrm{ml})\left({ }^{*} P<0.01\right)$, but not fibronectin (FN, $10 \mu \mathrm{g} / \mathrm{ml})$. Protein concentrations in the subsaturated linear range of adhesion as determined in $(A)$ were used to coat wells. Fluorescence intensity unit ( $\mathrm{Y}$ axis) represents the mean intensity at $490 \mathrm{~nm}$ excitation/530 nm emission after calcein AM staining. Statistical significance is indicated by an asterisks $\left(^{*}\right)$ with $P<0.01$ and compares individual PAR1 thrombin (Thr) or TRAP6 stimulated samples to control untreated samples. modestly but significantly decreased $\left({ }^{*} P<0.01\right.$, Fig. 1B).

Since integrins are responsible for cell-ECM adhesion, we then examined the integrin expression profile of PC-3 cells. Analysis of cell surface expression of integrin subunits by flow cytometry showed that PC-3 cells had the highest overall expression of the $\beta 1$ integrin subunit (Fig. 2). The collagen-binding integrin subunits $\alpha 2$ and $\alpha 3$ were more abundant than the laminin-binding integrin subunits $\alpha 1, \alpha 6$, and $\beta 4$ and the fibronectin-binding integrin subunit $\alpha 5$. The vitronectin receptors $\alpha \mathrm{v} \beta 3$ and $\alpha v \beta 5$ integrins were the least detected. Thus, the expressions of cell surface integrins supported the PC-3 cell adhesion profile shown in Figure 1A. However, PAR1 stimulation of cells did not affect expression of surface integrins (Fig. 2).

\section{PAR1 Stimulation Causes Retraction of the Actin Cytoskeleton}

To determine whether PAR1 activation influenced actin reorganization, PC-3 cells were immunostained with fluorescence conjugatedphalloidin (Fig. 3A,E,I,M). Treatment of PC-3 cells with thrombin or TRAP6 caused retraction of the actin cytoskeleton, and cells demonstrated numerous microspike extensions from the cell body. PAR1 activation with $10 \mathrm{nM}$ thrombin induced a more pronounced presence of microspikes than with $2 \mathrm{nM}$ thrombin. Furthermore, unstimulated PC-3 cells appeared more flattened compared to PAR1-activated

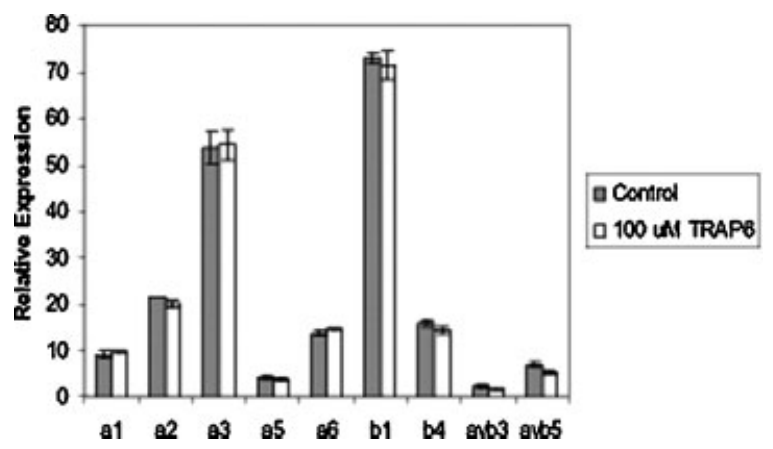

Fig. 2. Expression of cell surface integrins are unaffected by PAR1 activation. Flow cytometry analysis of cell surface integrin expression was performed to compare untreated control, $10 \mathrm{nM}$ thrombin (Thr)-, and $100 \mu \mathrm{M}$ TRAP6 (TRAP)-stimulated PC-3 cells. Relative expression ( $\mathrm{Y}$ axis) represents the mean fluorescence intensity for each sample. Data points represent mean \pm standard deviation $(\mathrm{n}=3)$. 


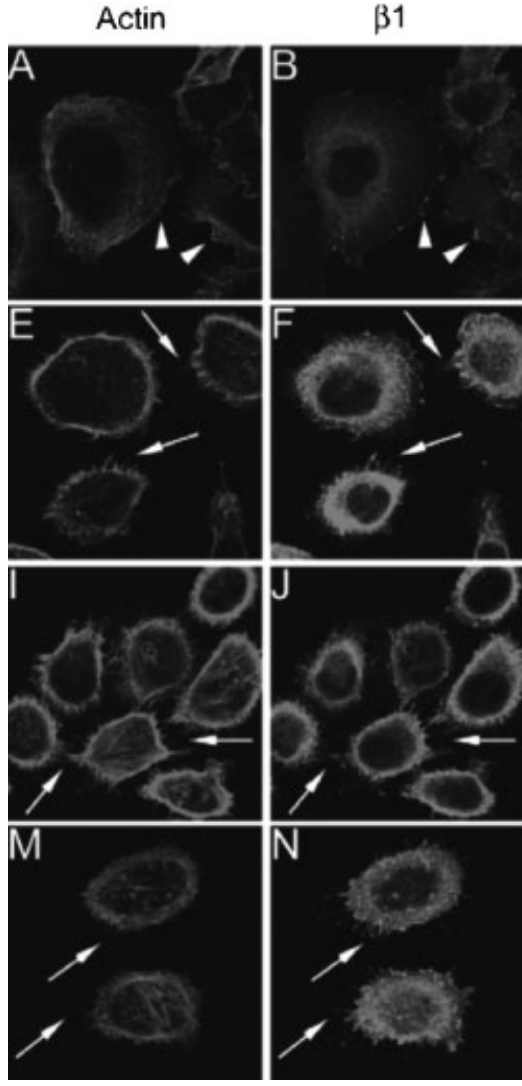

Fig. 3. PAR1 activation induces changes in cell morphology. PC-3 cells grown overnight on collagen I-coated glass coverslips were treated with thrombin for $2 \mathrm{~h}$ in serum-free RPMI-1640 followed by staining with AlexaFluor568-conjugated phalloidin (for actin), mouse monoclonal anti- $\beta 1$ integrin antibody/CY5conjugated goat anti-mouse secondary, or FITC-conjugated antiphosphotyrosine $(\mathrm{pY})$ antibody prior to confocal microscopy. Representative images of control untreated cells (A-D), 2 nM

cells, suggesting that PAR1 activation caused cell rounding. Since focal adhesion proteins are generally activated by tyrosine phosphorylation, we used anti- $\beta 1$ integrin (Fig. $3 \mathrm{~B}, \mathrm{~F}, \mathrm{~J}, \mathrm{~N}$ ), and anti-phosphotryosine 4G10 (Fig. 3C, G,K,O) monoclonal antibodies to determine whether PAR1 activation contributed to changes in focal adhesion organization. In untreated control cells actin, $\beta 1$ integrins, and phosphotyrosine colocalized at the broad edges of the cells at the focal adhesions (Fig. 3A-D, arrowheads). Stimulation with thrombin or TRAP6 caused changes in $\beta 1$ integrin and phosphotyrosine distribution within the cells (Fig. 3E-P). Stronger signals were observed around the perinuclear regions within the actin contractile ring. Colocalization was observed within the protruding microspikes, but not on the cell edges (arrows).

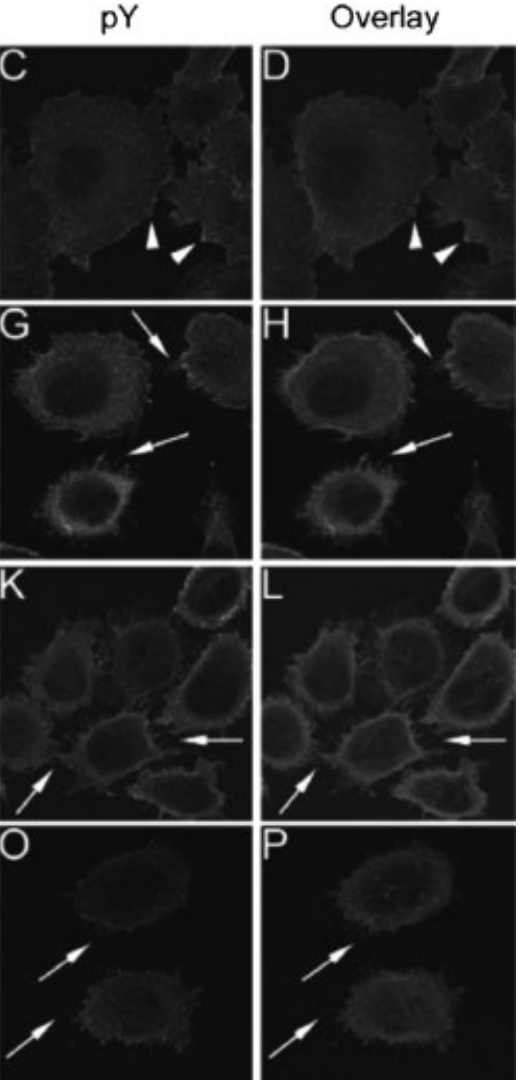

thrombin-treated cells $(\mathbf{E}-\mathbf{H}), 10 \mathrm{nM}$ thrombin-treated cells $(\mathbf{I}-\mathbf{L})$, and $100 \mu \mathrm{M}$ TRAP6-treated cells $(\mathbf{M}-\mathbf{P})$ were captured at $60 \times$ magnification. Images of Actin (red), Cy5-labeled $\beta 1$ integrin (pseudocolored blue), and phosphotryosine (green) were overlayed to facilitate visualization of colocalization $(\mathrm{D}, \mathrm{H}, \mathrm{L}, \mathrm{P})$. Arrowheads represent focal adhesions and arrows indicate microspikes and areas of colocalization.

\section{Rho GTPases Are Activated in Response to PAR1 Stimulation}

As changes in actin cytoskeletal organization are regulated by Rho GTPases, we measured the activities of RhoA, Rac, and Cdc42 in response to PAR1 stimulation. Using a GSTRBD fusion protein pull-down assay, we demonstrated that RhoA was rapidly activated (RhoAGTP) within 1 min of PAR1 stimulation with $10 \mathrm{nM}$ thrombin and remained activated by approximately twofold for at least $1 \mathrm{~h}$ (Fig. 4). Similarly, thrombin treatment-induced Cdc42 activation (Cdc42-GTP) within $5 \mathrm{~min}$, but declined to basal level by $30 \mathrm{~min}$ as shown by using a GTP-PAK fusion protein pull-down assay. However, there was no change in the level of Rac activation. Similar activation profiles were observed when cells were treated 

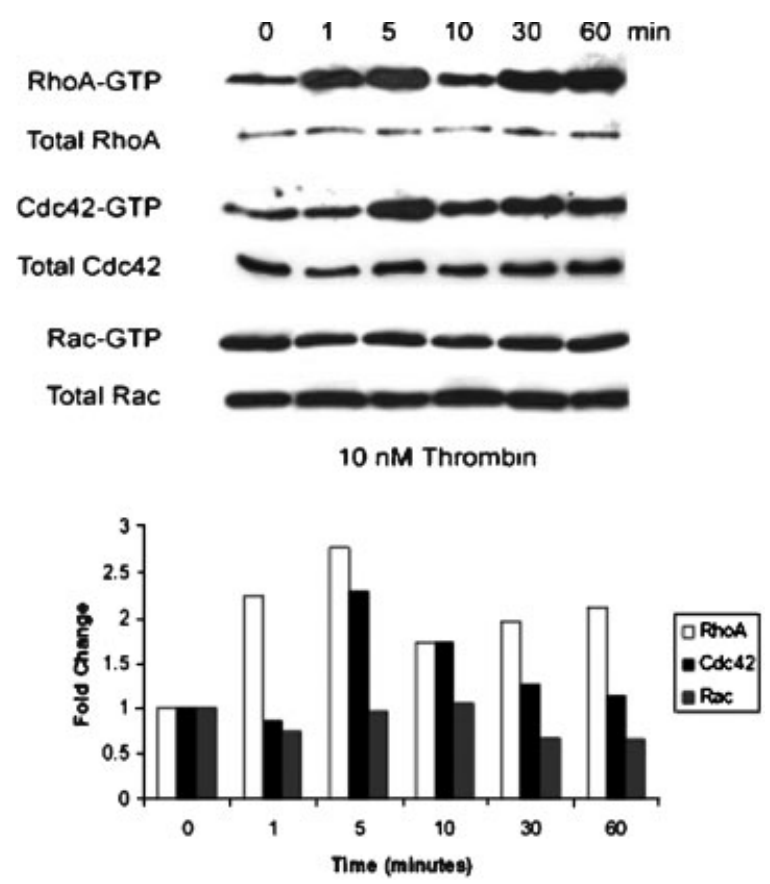

Fig. 4. Rho/Rac/Cdc42 activity in PAR1-stimulated PC-3 cells. Cell lysates collected at $0,1,5,10,30$, and $60 \mathrm{~min}$ after stimulation with $10 \mathrm{nM}$ thrombin were used to perform Rho GTPase pull-down assays. Total amount of each protein was determined from $20 \mu \mathrm{g}$ of total cell lysates. Fold-change in activation was calculated by analyzing the band intensity and adjusted as a ratio to untreated control.

with $2 \mathrm{nM}$ thrombin and $100 \mu \mathrm{M}$ TRAP6 (data not shown).

\section{PAR1 Stimulation Decreases Random Cell Motility}

To investigate the role of PAR1 activation on cell movement, we utilized the wounded monolayer assay to assess PC-3 cell motility on ECM component proteins. PAR 1 activation with $2 \mathrm{nM}$ thrombin significantly decreased cell migration on plastic, collagen I, collagen IV, and laminin $(P<0.05$, Fig. 5A,B). There was also a trend toward decreased mobility with $10 \mathrm{nM}$ thrombin and $100 \mu \mathrm{M}$ TRAP6 treatments, although to a lesser extent than with the lower thrombin concentration. Cell motility on fibronectin was not affected.

\section{PAR1 Stimulation Enhances PC-3 Chemotactic Migration to CCL2}

To investigate the role of PAR1 stimulation on migration in response to CCL2, a known chemoattractant [Loberg et al., 2006], PC-3 cells were treated with $100 \mu \mathrm{M}$ TRAP 6 for $24 \mathrm{~h}$ prior to the migration experiments. Stimulation of
PAR1 resulted in a significant increase in migration towards CCL2 $(100 \mathrm{ng} / \mathrm{ml})$ compared to unstimulated cells $(P<0.01$, Fig. 6$)$.

\section{DISCUSSION}

We have previously shown that bone-derived prostate cancer cells overexpress functional PAR1 receptor compared to soft tissue-derived prostate cancer cells and normal prostate epithelial cells [Chay et al., 2002]. In this article, we begin to investigate the effects of PAR1 activation on the metastatic properties of prostate cancer cells. PAR1 activation occurs through thrombin cleavage at the receptor extracellular amino terminus, thereby unmasking a new tethered ligand which serves as an intramolecular activator [Coughlin, 1999]. Hence, this activation is irreversible, and PAR1 signaling can therefore only be terminated by intracellular receptor recycling and degradation. As PC-3 cells express both PAR1 and PAR4 (data not shown), stimulation with thrombin activates both intracellular signaling pathways. Therefore, we also utilized the synthetic activator TRAP6 which encodes the cleaved amino-terminus of the PAR1 receptor and exclusively targets PAR1. Activation with thrombin was performed at 2 and $10 \mathrm{nM}$ concentrations, equivalent to physiological and pharmaceutical levels, respectively [Huang et al., 2000]. Activation with $100 \mu \mathrm{M}$ TRAP6 was chosen as this concentration mimics calcium release with $10 \mathrm{nM}$ thrombin [Darmoul et al., 2003].

Cells interact with the microenvironment through the cell surface integrins receptor which mediates cell adhesion to the ECM. Signal transduction through the integrins has been shown to play a role in prostate cancer metastasis [Tantivejkul et al., 2004]. We demonstrated that cell adhesion to collagens I and IV and laminin was decreased by PAR1 activation. In addition, we showed that the expression of cell surface integrins correlated with PC-3 cell adhesion profiles and was consistent with previous findings for these cells [Haywood-Reid et al., 1997]. Since PC-3 cells were derived from a prostate cancer bone metastasis, it is not surprising that these cells expressed the highest levels of integrin subunits associated with collagen binding (e.g., $\alpha 2$, $\alpha 3$, and $\beta 1$ ). Adhesion to fibronectin was not affected by PAR 1 activation most likely because 
a
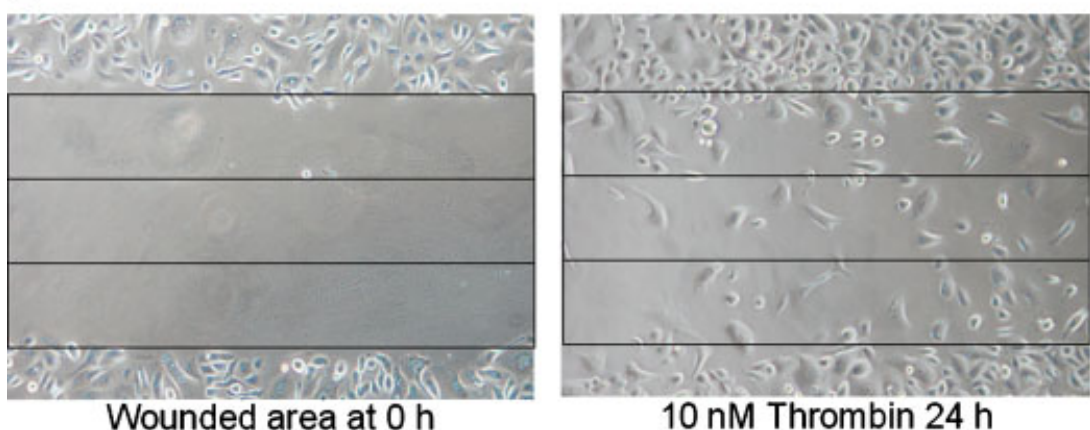

$10 \mathrm{nM}$ Thrombin $24 \mathrm{~h}$

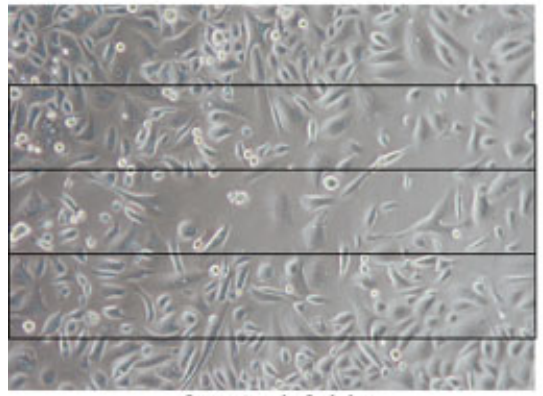

Control $24 \mathrm{~h}$

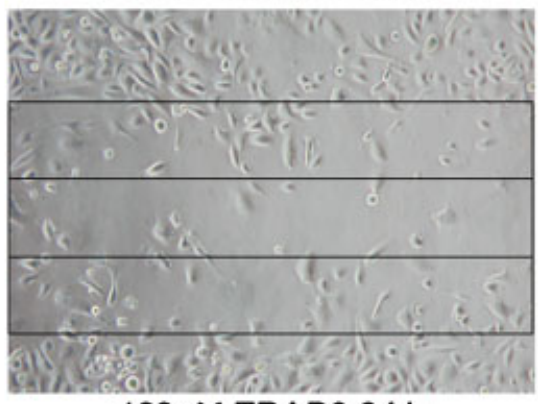

100 $\mu \mathrm{M}$ TRAP6 $24 \mathrm{~h}$

B

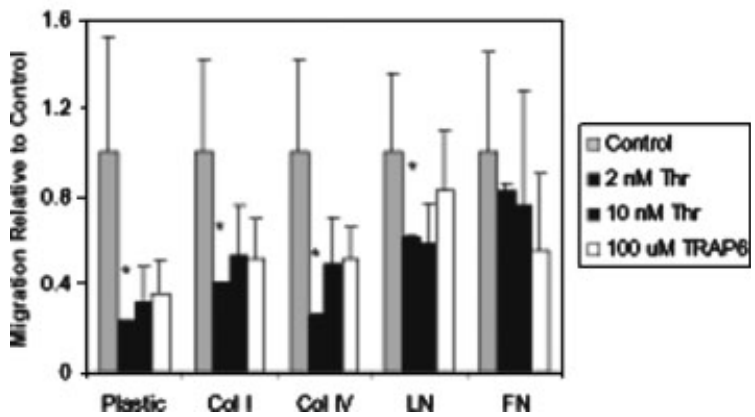

Fig. 5. PAR1 activation by thrombin reduced random cell motility. Wound assay was performed on cells cultured to $80-100 \%$ confluency on untreated (Plastic), collagen I- (Col I), collagen IV- (Col IV), laminin(LN), and fibronectin-coated (FN) tissue culture plates. A: The images represent the wounded areas at 0 and $24 \mathrm{~h}$ of incubation with or without thrombin. B: Quantification of the cells that have migrated into the wound demonstrated that treatment with $2 \mathrm{nM}$ thrombin significantly decreased cell migration on plastic, collagen I, collagen IV, and laminin $\left({ }^{*} P<0.05\right)$.

fibronectin integrin receptor $\alpha 5$ subunit was expressed at a lower level compared to collagen and laminin receptors. Similarly, vitronectin receptors $(\alpha \mathrm{v} \beta 3$ and $\alpha \mathrm{v} \beta 5)$ were the least expressed on PC-3 cells, probably accounting for the insignificant adhesion of PC-3 cells to vitronectin compared to other proteins in this study.

Despite detecting decreased adhesion of PAR1-activated prostate cancer cells to ECM components, we did not identify concomitant changes in cell surface expression of integrin receptors suggesting that PAR 1 activation may modulate integrin function and organization through other mechanisms. The engagement of the integrins to ECM proteins activates a variety of intracellular signaling through the protein tyrosine kinases associated with the focal adhesion complex, such as focal adhesion kinase, paxillin, $\mathrm{p} 130^{\mathrm{Cas}}$, and phosphatidylinositol 3-kinase [Giancotti and Ruoslahti, 1999]. Activation of the focal adhesion through tyrosine phosphorylation is necessary to provide traction for migration on ECM proteins. We investigated changes in focal adhesion organization by immunofluorescence staining of actin 


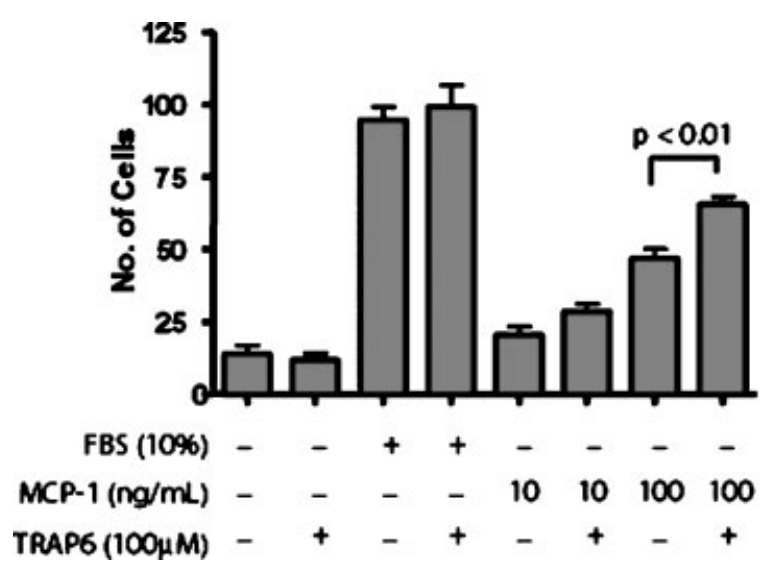

Fig. 6. PAR1 activation by thrombin enhances migration towards CCL2. Increasing concentrations of CCL2 (1-100 ng/ $\mathrm{ml}$ ) or conditioned media was added to the lower chamber of a 24-well plate. Cells were harvested and resuspended in serum free media at $5 \times 10^{4}$ cells $/ \mathrm{ml}$. Cells $\left(2.5 \times 10^{4}\right)$ were added to the upper chamber of the transwell insert and incubated for $24 \mathrm{~h}$ at $37^{\circ} \mathrm{C}$ and $5 \% \mathrm{CO}_{2}$ atmosphere. At the end of the incubation period, the cells were fixed with $4 \%$ formaldehyde in PBS for $5 \mathrm{~min}$ and non-adherent cells were removed. Cells which had migrated to the underside of the insert were stained with $0.5 \%$ crystal violet and counted using an inverted microscope. Stimulation of PAR1 resulted in a significant increase in migration towards CCL2 $(100 \mathrm{ng} / \mathrm{ml})$ compared to unstimulated cells $(P<0.01)$.

stress fibers, $\beta 1$ integrin subunits, and tyrosinephosphorylated proteins. Our results showed that upon activation with thrombin, colocalization of actin, $\beta 1$ integrin, and tyrosine-phosphorylated protein was lost, suggesting a disruption of focal adhesions consistent with our observations of rounding up in treated cells.

Activation of RhoA is essential for focal adhesion assembly in response to cell stimulation [Ridley and Hall, 1992]. The GPCR PAR1 has been shown to activate RhoA through $\mathrm{G} \alpha 12$ / 13 and p115Rho-GEF thereby dynamically regulating actin cytoskeleton and focal adhesions [Whitehead et al., 2001]. PAR1-activated RhoA has been shown to induce cell rounding and neurite retraction in neuronal cells [Jalink et al., 1994]. In addition, thrombin-treated endothelial cells show cell contraction leading to endothelial cell barrier dysfunction [van Nieuw Amerongen et al., 2000]. Recently, it has been reported that PAR1 activation is mediated by LARG (leukemia-associated RhoGEF) in PC-3 cells and that transfection with LARG siRNA nearly abolishes thrombininduced PC-3 cell rounding response [Wang et al., 2004]. Furthermore, the cooperation of Rho, Rac, and Cdc42 is required to regulate cell motility. Activation of Cdc42 induces the formation of filopodia which establishes cell polarity by sensing chemotactic signals [Arthur and Burridge, 2001]. Rac coordinates focal adhesion assembly in the lamellipodium and causes membrane ruffling at the leading edge [Nobes and Hall, 1995]. Activated Rho then generates contractile forces that push a cell body toward the leading edge and initiate actin polymerization [Ridley, 2001]. We demonstrated that RhoA is activated by PAR1 stimulation with thrombin which induced cell contraction. In addition, Cdc42 was also initially activated and declined rapidly to basal level. Due to the fact that $\mathrm{Cdc} 42$ is known to regulate the formation of filopodia, it is not surprising that thrombin-stimulated cells have numerous microspikes along the cell periphery. Rac, however, was not affected by thrombin treatment. We have also demonstrated that random cell motility was reduced when cells were stimulated with thrombin but migration towards a known chemoattractant, CCL2, was enhanced.

Activation of PAR1 has been shown to increase the metastatic potential of many other types of cancer [Nierodzik et al., 1992; Henrikson et al., 1999; Darmoul et al., 2003]. Overexpression of PAR1 in metastatic prostate cancer suggests that it may be involved in disease progression. It has also been shown that PAR1 activation of RhoA in $\mathrm{LNCaP}$ cells was enhanced by dihydrotestosterone, emphasizing the importance of PAR1 signaling pathway in prostate cancer [Greenberg et al., 2003]. In this study, we have examined the role of PAR1 activation in the modulation of cell adhesion, motility, and actin organization. Our results suggest that PAR1 activation in PC-3 alters cell structure, causes a decrease in cell adhesion, and enhances migration. Recently, we reported that CCL2 is highly expressed and secreted by bone marrow endothelial (BME) cells and demonstrated that CCL2 from BME cells served as a potent chemoattractant of prostate cancer cells in vitro [Loberg et al., 2006]. These data point out the importance of differentiation between measuring motility and migration. In these experiments, PAR1 stimulation induced changes in cell structure that enhanced the migratory abilities of the prostate cancer cells, an important step in metastasis. These results suggest an interesting paradigm of bone-related events in prostate cancer such that upregulation of PAR1 and CCR2 (the CCL2 
high affinity receptor) on prostate cancer cells "primes" these cells to metastasize to sites of elevated CCL2 expression, that is, the bone microenvironment. These data, as well as the data of others, suggest that the presence of increased thrombin in cancer patients may contribute to tumorigenesis and metastasis. Further work is necessary to establish a link between PAR1, CCL2 expression, and prostate cancer bone metastasis.

\section{ACKNOWLEDGMENTS}

This work is supported in part by SPORE 1 P50 CA69568-06A1, RO1 CA102871, and NIH 1 P01 CA093900-01A2. Dr. Loberg is a SPORE Career Development Awardee. Dr. Pienta is an American Cancer Society Clinical Research Professor. The authors thank Dorothy Sorenson for her assistance with confocal microscopy and Karen Giles for manuscript preparation.

\section{REFERENCES}

Arthur WT, Burridge K. 2001. RhoA inactivation by p190RhoGAP regulates cell spreading and migration by promoting membrane protrusion and polarity. Mol Biol Cell 12:2711-2720.

Burridge K, Wennerberg K. 2004. Rho and Rac take center stage. Cell 116:167-179.

Chay CH, Cooper CR, Gendernalik JD, Dhanasekaran SM, Chinnaiyan AM, Rubin MA, Schmaier AH, Pienta KJ. 2002. A functional thrombin receptor (PAR1) is expressed on bone-derived prostate cancer cell lines. Urology 60: $760-765$.

Coughlin SR. 1999. How the protease thrombin talks to cells. Proc Natl Acad Sci USA 96:11023-11027.

Darmoul D, Gratio V, Devaud H, Lehy T, Laburthe M. 2003. Aberrant expression and activation of the thrombin receptor protease-activated receptor-1 induces cell proliferation and motility in human colon cancer cells. Am J Pathol 162:1503-1513.

Giancotti FG, Ruoslahti E. 1999. Integrin signaling. Science 285:1028-1032.

Gohla A, Harhammer R, Schultz G. 1998. The G-protein G13 but not G12 mediates signaling from lysophosphatidic acid receptor via epidermal growth factor receptor to Rho. J Biol Chem 273:4653-4659.

Greenberg DL, Mize GJ, Takayama TK. 2003. Proteaseactivated receptor mediated RhoA signaling and cytoskeletal reorganization in LNCaP cells. Biochemistry 42: 702-709.

Haywood-Reid PL, Zipf DR, Springer WR. 1997. Quantification of integrin subunits on human prostatic cell linescomparison of nontumorigenic and tumorigenic lines. Prostate 31:1-8.

Henrikson KP, Salazar SL, Fenton JW II, Pentecost BT. 1999. Role of thrombin receptor in breast cancer invasiveness. Br J Cancer 79:401-406.

Huang YQ, Li JJ, Karpatkin S. 2000. Thrombin inhibits tumor cell growth in association with up-regulation of p21(waf/cip1) and caspases via a p53-independent, STAT-1-dependent pathway. J Biol Chem 275:6462-6468.

Jalink K, van Corven EJ, Hengeveld T, Morii N, Narumiya S, Moolenaar WH. 1994. Inhibition of lysophosphatidateand thrombin-induced neurite retraction and neuronal cell rounding by ADP ribosylation of the small GTPbinding protein Rho. J Cell Biol 126:801-810.

Lind SE, Caprini JA, Goldshteyn S, Dohnal JC, Vesely SK, Shevrin DH. 2003. Correlates of thrombin generation in patients with advanced prostate cancer. Thromb Haemost 89:185-189

Loberg RD, Day LL, Harwood J, Ying C, St. John LN, Giles R, Neeley CK, Pienta KJ. 2006. CCL2 is a potent regulator of prostate cancer cell migration and proliferation. Neoplasia 8:578-586.

Macrez N, Morel JL, Kalkbrenner F, Viard P, Schultz G, Mironneau J. 1997. A betagamma dimer derived from G13 transduces the angiotensin AT1 receptor signal to stimulation of $\mathrm{Ca}^{2+}$ channels in rat portal vein myocytes. J Biol Chem 272:23180-23185.

Nierodzik ML, Kajumo F, Karpatkin S. 1992. Effect of thrombin treatment of tumor cells on adhesion of tumor cells to platelets in vitro and tumor metastasis in vivo. Cancer Res 52:3267-3272.

Nobes CD, Hall A. 1995. Rho, rac, and cdc42 GTPases regulate the assembly of multimolecular focal complexes associated with actin stress fibers, lamellipodia, and filopodia. Cell 81:53-62.

Offermanns S, Laugwitz KL, Spicher K, Schultz G. 1994. G proteins of the G12 family are activated via thromboxane A2 and thrombin receptors in human platelets. Proc Natl Acad Sci USA 91:504-508.

Ridley AJ. 2001. Rho GTPases and cell migration. J Cell Sci 114:2713-2722.

Ridley AJ. 2004. Rho proteins and cancer. Breast Cancer Res Treat 84:13-19.

Ridley AJ, Hall A. 1992. The small GTP-binding protein rho regulates the assembly of focal adhesions and actin stress fibers in response to growth factors. Cell 70:389-399.

Sander EE, van Delft S, ten Klooster JP, Reid T, van der Kammen RA, Michiels F, Collard JG. 1998. Matrixdependent Tiam1/Rac signaling in epithelial cells promotes either cell-cell adhesion or cell migration and is regulated by phosphatidylinositol 3-kinase. J Cell Biol 143:1385-1398.

Tantivejkul K, Vucenik I, Shamsuddin AM. 2003. Inositol hexaphosphate (IP6) inhibits key events of cancer metastasis: I. In vitro studies of adhesion, migration and invasion of MDA-MB 231 human breast cancer cells. Anticancer Res 23:3671-3679.

Tantivejkul K, Kalikin LM, Pienta KJ. 2004. The dynamic of prostate cancer metastasis to bone. J Cell Biochem 91:706-717.

van Nieuw Amerongen GP, van Delft S, Vermeer MA, Collard JG, van Hinsbergh VW. 2000. Activation of RhoA by thrombin in endothelial hyperpermeability: Role of Rho kinase and protein tyrosine kinases. Circ Res 87:335-340.

Wang Q, Liu M, Kozasa T, Rothstein JD, Sternweis PC, Neubig RR. 2004. Thrombin and lysophosphatidic acid receptors utilize distinct rhoGEFs in prostate cancer cells. J Biol Chem 279:28831-28834.

Whitehead IP, Zohn IE, Der CJ. 2001. Rho GTPasedependent transformation by $\mathrm{G}$ protein-coupled receptors. Oncogene 20:1547-1555. 